\title{
Argumentação e Polêmica nas Redes Sociais: o Papel de Violência Verbal
}

Argumenation and Polemics in Networks: the Role of Verbal Aggression

\section{Ana Lúcia Tinoco Cabral}

\author{
Nelci Vieira de Lima
}

Universidade Cruzeiro do Sul - Campus Anália Franco - São Paulo - Brasil

\begin{abstract}
Resumo: O presente trabalho apresenta uma análise da construção da polêmica gerada por artigo de opinião publicado em um blog e difundido pela rede social, Facebook e comentários criticando o posicionamento do blogueiro. Focalizando a dissensão na Web, o trabalho analisa a instauração da polêmica e as interações verbais conflituosas nas redes sociais especialmente as manifestações linguísticas da violência verbal por parte dos usuários, destacando seu papel na construção argumentativa de um discurso que visa a criticar o post. O quadro teórico que dá suporte às análises contempla o Estudo da Polêmica (Amossy, 2011 e 2014) em confluência com pesquisas sobre a violência verbal (Brown \& Levinson, [1978]1999; Locher \& Watts, 2008; Culpeper, 2008; Bousfield, 2008; ), sempre observando o caráter argumentativo das marcas linguísticas.
\end{abstract}

Palavras-chave: Argumentação; Polêmica; Violência verbal; Redes sociais.

Abstract: This paper presents an analysis of the construction of polemics generated by an opinion article published on a blog and spread by the social network, Facebook, and comments criticizing the blogger positioning. Focusing on the dissension on the Web, the paper analyzes the establishment of polemics and conflicting verbal interactions on social networks especially linguistic manifestations of verbal aggression by users, highlighting their role in the argumentative construction of a discourse that aims to criticize the post. The theoretical framework that supports the analysis includes the study of Polemics (Amossy, 2011 and 2014) in confluence with research on verbal aggression (Brown \& Levinson, [ 1978 ] 1999; Locher \& Watts, 2008; Culpeper, 2008; Bousfield, 2008; ) , always observing the argumentative role of language marks.

Keywords: Argumentation; Polemics; Verbal violence; Social networks. 


\section{Introdução}

Os avanços tecnológicos ocorridos nos últimos tempos incorporaram à sociedade novos modos de interação, que se constituem a partir da tríade homem/máquina/homem. Assim, as conversações face a face, aos poucos, vêm sendo substituídas pelas interações virtuais. As conversas em cafés, restaurantes, ou mesmo por telefone, são substituídas por conversas em redes sociais. A palavra falada vai sendo sobreposta pela palavra escrita. Nesse cenário, ganham espaço, cada vez maior, os smartphones, com suas multifuncionalidades. A Internet vai na palma da mão, e com ela as possibilidades de interação social.

Isto posto, é preciso dizer que as pessoas tomaram posse da palavra, o que nos permite inferir que o mundo virtual se concretiza a partir da escrita. As interações são diversas, desde conversas particulares ou em grupo, em aplicativos como o Whatsapp, até debates fervorosos, marcados por posicionamento político, no Facebook. É notável como a imersão nesse mundo repleto de tecnologias provocou mudanças comportamentais nas pessoas, e, uma delas é, justamente, a forma de se organizarem em grupo e de se perceberem perante ao outro. Assim, nas redes sociais, as relações vão sendo estabelecidas por meio de interesses comuns, ainda que as pessoas não se conheçam pessoalmente.

A necessidade de pertencer a um grupo leva, por sua vez, à construção do perfil virtual, que funciona como a identidade do usuário, de grande importância para que novos amigos sejam adicionados à sua rede. Quanto maior o número de amigos virtuais, maior será a popularidade da pessoa, que receberá muitas curtidas em seus posts, e até mesmo compartilhamentos. $O$ fato de pertencer a um grupo virtual fortalece a identidade e propicia a tomada de posição frente aos temas trazidos nos posts, que num movimento cíclico, contribui para a cristalização dessa identidade. Cristalizam-se também as opiniões, que se tornam fortes e definidas, uma vez que encontram apoio no grupo ao qual a pessoa se insere. Dessa forma, as redes sociais vão se constituindo como palco de interações que, por vezes, se fazem mais conflituosas do que harmônicas. O que pode ser comprovado por meio da observação e análise do corpus selecionado para este trabalho.

A observação de interações conflituosas na Web conduziu nosso interesse pelas polêmicas nas redes sociais, e as estratégias linguísticas empregadas nesses contextos. Entendemos, com Amossy (2011, p.27) que, sendo a polêmica, "un mode verbal de gestion des conflits qui met l'accent sua l'antagonisme et l'incommensurabilité des points de vues opposés", ela interessa às pesquisas voltadas para as estratégias argumentativas. Elegemos, assim, como corpus para este estudo um artigo de opinião publicado em um blog e os comentários no Facebook relativos a ele.

Com respeito ao estatuto da polêmica, cabe lembrar, com Amossy (2014), que a sociedade do século XXI é afeita ao espetáculo; as polêmicas tornam-se assim atraentes porque nelas há vencedores pelos quais podemos torcer e há perdedores que são ridicularizados, desprezados. Diante dessa espetacularização dos conflitos, muitos jornalistas, segundo a autora, fabricam polêmicas, por meio de um discurso que incita ao contraditório, ao choque de opiniões.

De antemão, consideramos importante esclarecer a forma como se deu a delimitação do corpus e também a maneira como ele foi coletado. Assim, serviram-nos de análise textos expostos em dois ambientes virtuais, amarrados entre si por um link, ou seja, o Blog do Sakamoto, mantido no site UOL Notícias e a página do jornalista e blogueiro no Facebook, caracterizada como Figura Pública. De um lado, temos 0 artigo de opinião, intitulado $O$ governo não faz a mínima ideia do que seja terrorismo, escrito e publicado pelo jornalista e doutor em Ciência Política Leonardo Sakamoto, no blog em questão. De outro, temos os textos dos comentários deixados na página do jornalista no Facebook, a respeito do post do mesmo artigo. A popularidade do blogueiro na rede social faz com que ela seja usada 
como veículo de divulgação dos textos publicados em seu blog. Observamos que cada texto novo no blog corresponde a uma nova postagem no Facebook, o que traz visibilidade aos artigos e se comprova pelos números: a página, até a dada da coleta do corpus, tinha 473.728 seguidores. Já o post tinha 4.800 mil curtidas, 1.364 compartilhamentos e 281 comentários, sem contar as respostas dos internautas a alguns comentários. Conforme expomos mais à frente, na parte das análises, o próprio blog se constitui como polemizador, devido não só à temática politizada de seu conteúdo, mas, principalmente, às estratégias argumentativas postas em prática pelo blogueiro, cuja intencionalidade, intrínseca ao texto, nem sempre está em convencer o leitor, mas também, em proporcionar a discordância e o debate. Duas perguntas orientam nossa investigação: Quais estratégias linguísticas são utilizadas pelo jornalista e blogueiro na construção de sua argumentação, visando a fomentar a polêmica? Quais estratégias argumentativas são utilizadas para marcar os conflitos estabelecidos em interações virtuais, especificamente em espaços das redes sociais?

Isto posto, e considerando o caráter polêmico do corpus em análise, nosso objetivo é verificar as estratégias linguísticas empregadas, de um lado pelo blogueiro para instaurar a polêmica, instigando a participação dos usuários, e, de outro, comentários contrários ao posicionamento do blogueiro, para observar as estratégias utilizadas para manter a polêmica. A delimitação do corpus a comentários contrários se deve aos limites de extensão do artigo, mas também ao fato de que é neles que se marca a primeira característica da polêmica, que, segundo Amossy (2011, p.26) é "l'opposition marquée des discours" . Para o presente trabalho, fundamentamos nossas análises nos estudos sobre a polêmica (Amossy, 2011 e 2014) e, a partir deles, em pesquisas sobre a violência verbal ( Brown \& Levinson, [1978]1999; Locher \& Watts, 2008; Culpeper, 2008; Bousfield, 2008; ), sempre observando o caráter argumentativo das marcas linguísticas.
O trabalho divide-se em quatro partes, além dessas considerações iniciais e das finais: a primeira, aborda teoricamente questões relativas à polêmica; a segunda, desenvolve brevemente alguns conceitos relativos à violência verbal; a terceira expõe as análises do post do jornalista e blogueiro, verificando as estratégias utilizadas para instaurar a polêmica; a quarta analisa a linguagem presente nas reações contrárias ao post, destacando a violência verbal linguisticamente marcada.

\section{Mídias digitais e polêmica}

A emergência dos espaços digitais proporcionou amplas possiblidades de divulgação de informações e de proliferação de tomadas de posição. A construção de opiniões e de identidades acontece nos espaços públicos das mídias digitais e das redes sociais. Com efeito, conforme observa Amossy (2014), as mídias privilegiam a polêmica, e esta parece suscitar grande interesse dos usuários. Relativamente às tomadas de posição nas mídias digitais, vale retomar Cabral et al (2015), para quem o ambiente digital e a condição de participante de uma discussão, aliados ao fato de os usuários poderem assumir uma identidade fictícia, permanecendo anônimos, Ihes chancela a exposição mais espontânea de seus pontos de vista. Nesse contexto, o usuário expõe de forma mais explícita suas opiniões, podendo tornar-se agressivo até. É como se a máquina o protegesse de uma contra agressão direta e ele se sentisse livre para agir mais violentamente. Simultaneamente, conforme já destacado por Cabral (2008), os espaços Web dão uma sensação de proximidade, uma vez que tudo se torna facilmente acessível. Essa sensação permite que as pessoas interajam de forma mais espontânea, e a linguagem se torne mais próxima da linguagem coloquial, familiar. Esse contexto conduz as pessoas a exporem suas emoções de forma mais livre, tanto as positivas como as negativas; as pessoas se mostram mais nos espaços Web e os conflitos se tornam mais visíveis, dando lugar a embates polêmicos. 
Polêmica é um conceito que, de acordo com Amossy (2011, p.27), envolve a "polarisation extrême et la confrontation radicale de positions antagonistes" - A polêmica origina-se de um conflito de opiniões. Com efeito, o que caracteriza a polêmica é o ato de marcar a oposição, ou, como afirma Amossy (2011, p.27), “l'antagonisme et l'incommensurabilité des points de vue opposés" . Se a violência está frequentemente associada à polêmica é porque esta se define por ser uma manifestação discursiva sob forma de choque, de confronto brutal de posições (Amossy, 2014).

A polêmica, segundo Amossy (2014), se dá no espaço público; antigamente eram as praças públicas, atualmente, são os ambientes digitais, como: Facebook , Twitter, Instagram, WhatsApp, Telegram, Youtube, outrora o Orkut, entre outros. Os espaços públicos digitais trouxeram uma nova dimensão temporal para a divulgação de informações e, consequentemente, da expressão de tomadas de posição frente as informações que circulam na rede. Tudo se torna público rapidamente na Web. Essa particularidade dos ambientes digitais possibilita também a ampliação das relações. Nesse contexto, torna-se ainda mais pertinente o postulado de Amossy (2011) de que a polêmica exacerba o confronto que dá origem à atividade argumentativa. Segundo Amossy (2014), três são as características do discurso polêmico: a dicotomização do discurso; a desqualificação do outro; o apelo às emoções.

Amossy (2011) observa que a polêmica radicaliza pontos de vista em choque, o que determina a primeira característica da polêmica, ou seja, a dicotomização do discurso. A dicotomização se apresenta sob a forma da polarização de posições: há na polêmica um "eu" que opõe ao "outro", ou a "ele", mostrando que as posições assumidas por cada um são inconciliáveis. Segundo Amossy (2014), a dicotomia inviabiliza o acordo entre os participantes, uma vez que ela tem por resultado congelá-los em suas posições antagônicas. Torna-se assim importante, do ponto de vista argumentativo para o discurso polêmico, marcar a diferença.
Uma forma de marcar a diferença consiste em desqualificar os argumentos do outro, o que, no dizer de Amossy (2014) leva ao descrédito em relação ao adversário, por atribuir-lhe má fé; pode-se mesmo desqualificar o outro na sua pessoa, deslegitimandoo. A violência verbal assume então um papel importante como estratégia do discurso polêmico, pois, ao agredir o adversário, nós o estamos, de alguma forma, o desqualificando.

Outra estratégia, menos agressiva, consiste em refutar os argumentos do outro, indicando que seu discurso não merece crédito. O discurso polêmico precisa estar marcado linguisticamente, por meio de estratégias linguísticas que permitem anular 0 discurso do outro, como: a negação, a reformulação orientada, a ironia, a deformação dos propósitos (AMOSSY, 2014, P.62); a tais marcas propostas pela estudiosa, podemos acrescentar os qualificativos de valor negativo, pois a desqualificação da pessoa do adversário conduz ao descrédito e permite anular a força de seus argumentos. Essa inclusão vai também ao encontro do postulado de Micheli (2011) de que, no discurso polêmico, as representações são carregadas de julgamentos de valor.

A dicotomização do discurso e a desqualificação do adversário implicam, de acordo com Amossy (2014), sujeitos profundamente envolvidos no debate, o que quer dizer que o discurso se apresenta subjetivamente marcado, com uma tomada de posição clara, por meio de afirmações categóricas, negações, exclamações, exposição de estados emocionais. Podemos afirmar que as emoções assumem na polêmica um papel importante do ponto de vista argumentativo, pois elas constituem uma forma de o sujeito marcar uma tomada de posição, implicar-se no discurso.

\section{A violência verbal como estratégia para a polêmica}

Marcar a oposição implica, de certa forma, enfrentar o interlocutor e constitui um ato que fere, por si só, face negativa do outro (Brown e Levinson, 1999 [1978]), uma vez vai contra o desejo dele de ver 
suas opiniões aprovadas. Vale lembra que as ameaças às faces podem ser interpretadas como uma violência. Por isso é que, normalmente, procuramos atenuar a contraposição, procurando formas sutis de contra argumentar as razões do outro, afinal, como destaca Kerbrat-Orecchioni (2005, p.189), as sociedades procuram formas de preservar "o caráter harmonioso da relação interpessoal, em detrimento dos riscos de que implica qualquer encontro social". Essa preocupação, contudo, não exclui situações de violência explícita, inclusive aquelas nas quais os indivíduos têm o firme propósito de insultar e desqualificar o outro, instaurando uma situação de violência verbal. Como expusemos anteriormente neste trabalho, uma das estratégias do discurso das polêmicas, segundo Amossy (2014), constitui a desqualificação do adversário, que é uma violência à face do adversário. Sendo assim, as questões teóricas relativas à violência verbal são pertinentes para compreendermos as estratégias argumentativas da polêmica.

Não podemos ignorar que situações nas quais os interlocutores têm pouca intimidade entre si normalmente impõem maior preocupação em não agredir o outro; de outro lado, a maior proximidade, conforme já expuseram Kerbrat-Orecchioni (2005) Eggins (1994) e Cabral (2013 e 2014), chancela o uso de uma linguagem mais espontânea aumentando o risco de violência. As redes sociais têm a característica de tornar todos "amigos", portanto, relativamente próximos. Se não próximos, pelo menos virtualmente pertencentes ao mesmo grupo. Essa pretensa proximidade das redes sociais, conduzindo as pessoas a exporem sua vida íntima, tornando-a pública, parece também fazê-las sentiremse mais livres para expor suas opiniões, mesmo que estas sejam agressivas relativamente a outro usuário das redes sociais pertencente ao mesmo grupo.

Bousfield (2008) destaca o caráter proposital intencional dos atos de violência verbal. Isso quer dizer aquele que agride o outro, o faz com determinado objetivo, que pode ser, o de desqualificálo e, por extensão, desqualificar seus argumentos, anulando a validade deles. Culpeper (2008) também defende que o emprego de uma expressão verbal de caráter violento traz em si a intenção de agredir. Locher e Watts (2008) lembram que os comportamentos que extrapolam as normas sociais são avaliados negativamente, isto é, são considerados agressivos, ou insultuosos. Nas polêmicas, em que uma das formas de participação é a desqualificação do outro, a agressão se torna uma estratégia que precisa estar marcada, como, por exemplo, por um qualificador pejorativo que, segundo Kerbrat-Orecchioni (1997 [1980]) diz respeito a substantivos ou adjetivos usados para qualificar de forma depreciativa um indivíduo ou um grupo. Verificaremos no corpus a presença de enunciados pejorativos empregados pelo blogueiro para desqualificar os temas em discussão e os sujeitos participantes dos fatos relatados, no intuito de instaurar a polêmica; verificaremos outrossim, nos comentários, como os enunciados pejorativos são empregados argumentativamente, seja para desqualificar o próprio blogueiro; seja os argumentos dele, mantendo a polêmica instaurada, pela dicotomização e pela desqualificação.

\section{A instauração da polêmica por meio de estratégias argumentativas}

O Blog do Sakamoto, como dito anteriormente, tem caráter marcadamente político. Apresenta, além das publicações diárias dos artigos de opinião, sempre referentes a temas oriundos do cenário político brasileiro, um canal de vídeo, Havana Connection, no qual o jornalista é mediador de debates entre seus convidados. Interessa-nos, no entanto, a constituição argumentativa dos textos escritos e publicados no blog e como ele instiga a polêmica; para a presente análise, selecionamos o artigo intitulado O governo não faz a mínima ideia do que seja terrorismo. O espaço do blog não permite que os leitores comentem os textos, o que pode, no entanto, ser feito na página do jornalista no Facebook, já que esse é um meio de divulgação do blog. 
Salientamos que Leonardo Sakamoto é uma figura pública, conhecida por fazer um jornalismo engajado. A observação de alguns exemplos de títulos de posts do jornalista nos permite afirmar que ele assume a oposição aos políticos de direita:

(1) "Flexibilizar a CLT? Que tal flexibilizar a propriedade privada também?"

(2) "Este Congresso não tem credibilidade para definir os rumos do país"

(3) "Não sabem governar, são ruins de serviço ou estão tirando com a nossa cara?

(4) "Manual de como NÃO fazer diplomacia.

Ou a razão do mundo estar rindo de nós"

Como podemos notar, os títulos trazem em si marcas linguísticas de oposição ao governo estabelecido. Em três dos exemplos o jornalista faz uso do advérbio de negação, a primeira vez negando uma qualidade esperada para um governo, credibilidade, e as duas outras ocorrências negando ações esperadas para um governo: "não tem credibilidade", "não sabem governar", "não fazer diplomacia". Além da negação, ressaltamos a interrogação, que explicita a dúvida, especialmente quando a pergunta integra uma alternativa (ou). Destaque-se que a associação da pergunta com o marcador "ou" conduz a resposta para o segundo elemento da relação de escolha. $O$ jornalista sinaliza para o leitor que, embora considere a primeira alternativa como possivelmente válida, sua adesão vai preferencialmente para o segundo segmento apresentado.

Cumpre observar também 0 uso das expressões, "tirando com a nossa cara" e "rindo de nós", que inserem o interlocutor, o leitor usuário frequentador da página para o discurso. O usuário representa aí o povo brasileiro, ou, pelo menos, todos aqueles que visitam sua página, incluindo ele próprio. Há que que se ressaltar, ainda, o tom coloquial da primeira expressão, "tirando com nossa cara", que evidencia uma intenção de aproximação com o povo, pelo uso de uma expressão típica da linguagem popular. Devemos também lembrar que a gíria atenua a formalidade própria de textos escritos e no contexto digital, em que, conforme já expuseram Arcoverde e Cabral (2004), a linguagem oscila entre o oral e o escrito, entre o formal e informal; o blogueiro, ao utilizar expressões menos formais, mostra-se inserido em tal contexto e, simultaneamente, próximo de seus leitores.

Assim como nos títulos que observamos anteriormente, no título do post que nos serve de análise, a referência negativa ao governo é clara: "governo não faz a mínima ideia do que é terrorismo". O título do post traz uma dupla negativa: não faz a mínima. A dupla negação assume, conforme já mostrou Cabral (2016), importância argumentativa nos enunciados em que ocorre, uma vez que, segundo a autora, uma segunda marca de negação no enunciado, por seu caráter intensificador, constitui o traço pragmaticamente mais eficaz. É o caso de "mínima" no título em análise. "Mínima" ideia nega categoricamente a possibilidade de que, na avaliação do jornalista, o governo tenha alguma ideia do que seja terrorismo.

O episódio que serve de tema para o texto é a prisão, pela Polícia Federal, de dez brasileiros suspeitos de estarem envolvidos com o Estado Islâmico e de planejarem possível atentado terrorista durante as Olimpíadas 2016, sediadas pelo Brasil. Os suspeitos teriam sido investigados a partir de rastros deixados em interações virtuais no aplicativo Telegram. É preciso observar que atentados terroristas têm sido cometidos constantemente em diversos lugares do mundo, como Europa, Estados Unidos, Israel, entre outros, e estão por isso em pauta na mídia, o que, em tese, justifica a preocupação e atenção do governo mobilizando agentes federais.

Voltando a atenção para o artigo, foco desta análise, é possível perceber que estratégias linguísticas são utilizadas no próprio título, de forma a marcar a posição do blogueiro perante o tema em debate. Em primeiro lugar, como dito antes, há a desqualificação do governo, pois afirmar que ele "não faz a mínima ideia" sobre terrorismo é também atestar sua incompetência para tratar do problema.

Logo no primeiro parágrafo do texto (5), a prisão é categorizada como "estardalhaço midiático", e o sujeito da oração é o próprio governo, ou seja, foi o próprio governo que provocou o estardalhaço. Podemos destacar, nas escolhas linguísticas, a orientação avaliativa de caráter negativo por parte do 
jornalista: não apenas o substantivo estardalhaço, isto é, algo espalhafatoso, barulhento (Houaiss e Villar, 2011), mas também o verbo "provocou" que, ligado a "estardalhaço", assume um valor negativo. Além disso, os suspeitos são desqualificados pela expressão "dez zé manés", expressão popular definidora do sujeito sem visibilidade, sem valor na sociedade, "qualquer um" (ARANHA, 2002):

(5) A menos que algum fato novo apareça, $\underline{0}$ governo brasileiro provocou um estardalhaço midiático, nesta quinta (21), pelo fato da Polícia Federal ter prendido dez zé manés suspeitos de simpatizarem com grupos terroristas. (grifos nossos)

No parágrafo seguinte (6), notamos 0 distanciamento do enunciador, por meio da expressão "há quem diga", que faz com que se atribua a 'outros' a crença na capacidade do governo em garantir segurança e integridade aos envolvidos nos jogos olímpicos. Tal estratégia constitui mais uma forma de negação, pois, ao usar o pronome "quem", que "indica, exclamativamente, indeterminação quanto a uma pessoa" (NEVES, 2000, p. 573), o jornalista se exclui do grupo daqueles que dizem "que isso nos tranquiliza". Podemos afirmar que Sakamoto, ao contrapor-se ao dizer de "quem diga", explicita sua descrença na capacidade de o governo "garantir a segurança e a integridade dos atletas”, marcando sua posição de descrédito. Podemos ainda afirmar que, ao negar o dito por alguém, anula seu conteúdo, excluindo também o que havia de positivo nos termos 'segurança' e 'integridade', o que novamente desqualifica o governo:

(6) Há quem diga que isso nos tranquiliza por mostrar que o governo é capaz de garantir a segurança e a integridade de atletas, jornalistas, visitantes e brasileiros durante os Jogos Olímpicos - a serem realizados no Rio, em agosto. (grifos nossos)

Apresentamos a seguir dois outros excertos (7) (8) que merecem destaque em nossa análise. O blogueiro parece esclarecer o uso da expressão "estardalhaço midiático", segundo ele, provocado pelo governo; o governo era, então, foco de sua crítica, que nos excertos a seguir, recai sobre a mídia. Esta, segundo ele, pode "incentivar atentados reais", por meio da "divulgação gratuita", veiculada "acriticamente", "como se notícias fossem neutras". Como podemos observar, a própria seleção lexical culpabiliza a mídia - "rádio", "televisão", "Internet" pela ampla divulgação do fato objeto da crítica de Sakamoto:

(7) A divulgação gratuita obtida através de um caso como esse pode incentivar atentados reais por qualquer idiota que queira visibilidade - idiotas que podem não ter relação alguma com os fundamentalistas de sempre, mas agirem por conta própria guiados pelas ideias alheias ou por sua própria sede por sair da invisibilidade. (grifos nossos)

(8) Se algo causa impacto, é claro que será copiado. E rapidamente, por conta da informação circulando em tempo real, seja via rádio e televisão, seja pela internet. (grifos nossos)

Destacamos ainda, nos dois excertos (7) e (8), algumas escolhas lexicais que evidenciam o propósito de instigar a polêmica por parte de Sakamoto. Em (7), temos uma retomada do referente "Zé manés", instaurado no início do texto, por "idiotas"; estabelecese assim uma equivalência entre "Zé manés" e "idiotas". Os "Zé manés" foram presos, mas, na avaliação de Sakamoto, não devem ser de fato terroristas; "idiotas" seriam também não terroristas que por ventura podem cometer atentados pela necessidade de "visibilidade". O emprego de palavras de cunho mais agressivo para referir os indivíduos que são foco da polícia, no contexto da crítica às ações policiais promovidas pelo governo, parecem paradoxais na medida em que o blogueiro agride tanto aqueles que critica quanto aqueles cuja ação parece resguardar; elas se justificam, no entanto, pela polêmica. No contexto do Blog do Sakamoto, lugar de discussão política, a polêmica precisa prevalecer para manter o interesse dos usuários, que se manifestarão no Facebook.

Com base nas análises, cremos poder afirmar que as estratégias argumentativas postas em prática pelo jornalista e blogueiro confirmam o dizer de Amossy (2014) de que os discursos jornalísticos são, muitas vezes, geradores de polêmica. Um exemplo disso pode ser observado na contradição estabelecida no exemplo (8), ao criticar a mídia pela divulgação "gratuita" do fato, mesmo sendo 
participante ativo dessa crítica, haja vista a grande repercussão de seu texto nas mídias digitais. Criticar a própria prática é uma atitude que parece ter por objetivo instigar a polêmica.

Se marcar a oposição ao outro fere a sua face negativa (Brown e Levinson, 1999 [1978]), agredir os pares pode representar agredir a si próprio. Ao criticar a mídia e atividade de jornalistas, Sakamoto agride a face negativa deles, o que pode se configurar como um ato duplamente agressivo, pois ele não está criticando aqueles que normalmente são alvo de sua reprovação, a classe política, mas está expondo um posicionamento contrário à atividade da mídia, isto é, à sua própria atividade e àquela desenvolvida pelos seus pares. Sakamoto, na sequência, contrariando seu comentário agressivo, e, portanto, de maneira paradoxal, se esquiva do que afirmara anteriormente e, logo após criticar a atuação da mídia, acusando-a fazer divulgação "gratuita" de fatos, busca atenuar sua afirmação, como se desejasse corrigir seu ato violento:

(9) Não estou jogando a culpa no mensageiro ou dizendo que o mimetismo é a causa das desgraças do mundo, mas temos certa parcela de responsabilidade quando transmitimos fatos acriticamente, como se notícias fossem neutras, não houvesse contexto social e todos os receptores da informação compartilhassem dos mesmos valores. (grifos nossos)

O fato é que, conforme lemvra KerbratOrecchioni (2015), procuramos manter certa harmonia nas interações, e em especial com aqueles que consideramos nosso pares. Sakamoto é parte atuante da mídia; a crítica a ela também o atinge, e mais ainda, a crítica a ela o coloca numa posição de risco por violar a harmonia entre pares. Há, assim, a atenuação da crítica, negando uma possível interpretação negativa, que aliás seria de se esperar, dado o teor do texto, culpabilizando a mídia: "Não estou jogando a culpa no mensageiro ou dizendo que o mimetismo é a causa das desgraças do mundo".

Finalmente, ao encerrar o texto, no último parágrafo (10), mantendo o intuito de gerar polêmica, nova oposição é feita ao governo, e o contraste da ação versus sua importância pode ser marcada pela oposição posta na imagem da grandeza de um "canhão" em contraponto à pequenez da figura de um "passarinho". Assim, o blogueiro afirma:

(10) O governo usou um canhão para abater passarinho. Espero que não ajude a inflar os mesmos monstros que ele quer destruir.

Como podemos notar, o texto de Sakamoto é marcado linguisticamente por estratégias argumentativas que incitam a polêmica ao marcar um posicionamento claro, e, simultaneamente, manter um discurso caracterizado por palavras de cunho violento, não apenas contra o governo, foco de suas críticas, mas contra todos os sujeitos mencionados em seu texto: participantes da ação policial, inclusive os supostos criminosos, governo, meios de comunicação e pode-se inferir, até os usuários, principalmente aqueles que não concordam do ele. Fica assim instaurada a polêmica. A difusão do texto no Facebook gerou amplo debate, recheado de contra argumentações, marcadas por sua vez, pelas emoções e pela violência verbal; alguns comentários contrários ao posicionamento de Sakamoto são analisados na próxima sessão deste trabalho.

\section{Violência verbal na polêmica das redes sociais}

A capacidade de difusão daquilo que se compartilha nas redes sociais é ampla; um mesmo post é visto por centenas ou até milhares de pessoas, que, além de apertar o botão curtir, têm a possibilidade de manifestar suas opiniões, favoráveis ou contrárias a ele. Nesse contexto, os leitores ganham voz, interagem com o responsável pela postagem e entre si. Toda essa movimentação, na medida em que espelha tomadas de posição, tem caráter argumentativo, e, por estabelecer posicionamentos dicotômicos (contra e a favor) acaba por ampliar o caráter polêmico daquilo que já trazia em si certa dose de polêmica. Apenas para exemplificar, o texto do Blog que analisamos na sessão anterior gerou no Facebook, até a data da coleta do corpus 4.800 mil curtidas, 1.364 compartilhamentos e 281 comentários, sem contar as respostas aos comentários; alguns chegaram a ter até 30 respostas. Metaforicamente, podemos 
imaginar a situação polêmica analisada neste trabalho a uma árvore: o artigo de opinião analisado na sessão anterior seria o tronco da polêmica, cujos galhos formam-se no emaranhado dos comentários a ele ligados.

A análise dos comentários focalizará apenas aqueles que se manifestam contrários à opinião de Sakamoto, delimitados àqueles que fazem referência direta ao blogueiro ou ao texto do post. Focalizamos as marcas linguísticas da violência verbal e como elas funcionam como estratégias para a contra argumentação e manutenção da polêmica. Por razões de delimitação atendendo às exigências desta veículo, restringimos os exemplos analisados a 6 excertos a título de exemplificação, embora a leitura dos comentários em geral oferecesse material vasto de investigação.

Iniciamos as análise pelas marcas de violência verbal. Em (11), destacamos escolhas lexicais como: "são uns asnos", "cegamente saem vomitando pelos dedos":

(11) Existem pessoas que possuem posições políticas e aí cegamente saem vomitando pelos dedos por aí. A ação da PF foi coerente, legítima e proporcional sim, tudo de acordo com a lei. Mas existem uns petistas, como o Sakamoto, que prefere que esses "coitados amadores" continuem a se profissionalizar e realizarem seus atos deliberadamente. A ação da inteligência da PF está de parabéns sim, lei é para ser cumprida, quem fica criticando são uns asnos. (grifos nossos)

Asno, segundo Aranha (2002, p.37), diz respeito a imbecis, "pessoas destituídas de inteligência". É uma agressão verbal àqueles que criticam a PF, e Sakamoto entre eles. A expressão "vomitar pelos dedos", por sua vez, faz referência à atividade de escrita do blogueiro; é por meio da digitação que o blogueiro expõe suas ideias. Se, na avaliação do usuário elas equivalem a vômito, então elas servem apenas para serem desprezadas, como lixo. Ao comparar a palavras de Sakamoto a vômito, o usuário utiliza de forma explícita a violência verbal. Podemos afirmar que, no comentário (11), a linguagem utilizada marca a desqualificação do blogueiro e a agressão a ele. Além disso, ao afirmar que "existem pessoas que possuem posições políticas" o usuário refere-se implicitamente ao próprio Sakamoto, o que se confirma com a violenta crítica que expressa em seguida. Com base nessa reflexão, podemos afirmar, relativamente ao comentário (11), que o usuário, além de declarar sua posição contrária ao blogueiro, ataca a posição política dele "uns petistas, como Sakamoto".

A dicotomização de posições também é explicitada em (12):

(12) Esquerdista pensa assim, prefere que o mal aconteça para depois dizer "não se prepararam direito!" ou "esses eram lobos solitários, não representam o verdadeiro islã"... ahhhh todos vcs inclusive o Sakamoto vão arranjar o que fazer na vida. (grifos nossos)

Ao afirmar que "esquerdista pensa assim", o usuário se posiciona contrário a essa posição; está dizendo que 'logo, eu/interlocutor penso diferente, portanto não sou de esquerda. O comentário é finalizado com um enunciado injuntivo, cuja estrutura segue a fórmula das maldições (vá...): “....ahhhh todos vcs inclusive o Sakamoto vão arranjar o que fazer na vida". Essa construção explicita a posição do usuário frente ao blogueiro: inimigo. Podemos ainda afirmar que o usuário desqualifica o papel do jornalista e todos que, no Facebook, dedicaram seu tempo para escrever comentários, ficando implícito se sejam por isso, desocupados. O curioso é que o próprio usuário realiza essa ação.

As agressões por meio de qualificadores pejorativos podem ser observadas em (13), em que a alternância (ou) entre "burro" e "mal intencionado", usados como alternativas para categorizar o blogueiro deixam clara a intenção agressiva do usuário: ambas as escolhas propostas o avaliam negativamente, assim como "irresponsável", que também refere o blgueiro.

(13) Ou você é burro ou mal intencionado com esse seu texto simplista, com crítica gratuíta!! Tem que ser muito irresponsável pra publicar algo tão ruim, sem qualquer profundidade de análise dos fatos e das investigações!! (grifos nossos)

Trocadilhos com o nome do blogueiro explicitam a violência: "Sakabobagem" (14), "Sakarorra" (15), "Sakamorto" (16). A construção dos trocadilhos toma parte do nome do blogueiro e faz alusão à forma verbal sacar, no seu primeiro sentido 
de "tirar para fora bruscamente e com violência; arrancar, puxar em ameaça" e ao mesmo tempo à gíria 'sacar', forma já cristalizada pelo uso no português brasileiro e também dicionarizada; seu significado é "perceber pela inteligência, compreender, entender" (HOUAISS, 2001, p. 2491). Assim, fica estabelecido que o blogueiro de nada "saca", ou seja, 'sobre nada entende', portanto, seu discurso, assim como sua pessoa, deve ser desqualificado.

(14) Posar do lado da bandeira, tramar o atentado e encomendar uma AK47 é evidência frágil, Sr. Sakarolha??? Vc é sempre uma piada kkkkkkkkkkk

(15) Ô Leonardo Sakabobagem, os que nos últimos meses mataram centenas de pessoas, também eram Zés Manés, não precisa ser um profissional do crime para fazerem o que fizeram. Basta, serem loucos e terem colaboração de pessoas como você, ou seja, inocentes úteis, que em nada atrapalham ou siquer impedem suas ações criminosas.

(16) O governo não sabe o que é terrorismo. Quem sabe é o Sakamorto.

Além de agredir Sakamoto, há exemplos em que a agressão verbal se volta contra o conteúdo do post que gerou o comentário. Retomamos (13), comentário em que o texto de Sakamoto é avaliado pelo usuário como "simplista", "ruim" e portador de "crítica gratuita"; todos esses avaliativos têm caráter negativo e referem o conteúdo do texto, desqualificando-o, numa estratégia típica da polêmica (Amossy, 2014).

\section{Conclusão}

Neste trabalho, verificamos como as mídias digitais, e os profissionais que as utilizam como meio de comunicação com as massas, "fabricam" polêmicas ao expor, em seus textos, motivações para o confronto e como a linguagem favorece essa construção; analisamos, por outro lado, como o público responde a tais provocações, reagindo, muitas vezes, de forma violenta. Para tanto delimitamos a análise a comentários contrários ao defendido pelo jornalista no post.
Como ficou evidenciado, no desenrolar de nosso estudo, a instauração da polêmica foi instigada pelas estratégias argumentativas realizadas pelo próprio blogueiro, tal como Amossy (2014) destaca ocorrer no discurso jornalístico, que, segundo a autora, visa a provocar a polêmica. Como resposta a tal incitação, as relações conflituosas se multiplicaram nas redes sociais, como um fenômeno próprio da amplitude de divulgação nos espaços públicos da Web. A extensa divulgação faz ampliar as reações, que se tornam, em consequência, mais dicotomizada e, para assumir posições explicitamente contrárias ao posicionamento exposto pelo blogueiro, o emprego de marcas de violência verbal parece constituir uma estratégia argumentativamente eficaz, na medida em desqualificam o conteúdo do texto produzido pelo jornalista e agridem frontalmente a sua face, por meio da crítica pessoal.

As análises nos permitiram evidenciar a importância das escolhas verbais para a construção e manutenção da polêmica e a pertinência das marcas linguísticas de violência verbal para a análise argumentativa dos discursos inseridos no quadro da polêmica. Nossas análises nos permitem afirmar que, contrariamente ao que se pode defender, a polêmica interessa aos estudos da argumentação, não porque ela acaba por conduzir a um acordo de opiniões, que seria o objetivo final de toda argumentação, mas porque aquele que polemiza, o faz por meio da argumentação. Argumenta-se para polemizar, isto é, estratégias argumentativas são utilizadas no discurso polêmico para marcar um ponto de vista e igualmente para marcar a hostilidade perante o adversário. Pelas análises, podemos afirmar com Amossy (2011), que o objetivo daquele que polemiza não é convencer o outro, mas atrair a adesão de terceiros que, nas redes sociais, senão a adesão, pelo menos a atenção para a polêmica, considerando que o objetivo da polêmica não é adesão, mas a divulgação virulenta de opiniões em conflito; é o que mostra o volume de pessoas que "curtem" o post, e a respeito dele manifestam suas opiniões, favoráveis ou contrárias. 


\section{Referências}

AMOSSY, Ruth. Apologie de la polémique. Paris: PUF. 2014, $239 \mathrm{p}$.

La cohexistence dans le disssensus. La polémique dans les forums de discussion. SEMEN Révue de sémio-linguistique des textes et discours. 31. Toulouse : Presses Universitaires de FrancheComté, 2011. 204p. p.25-42.

ARANHA, J. Altair. Dicionário brasileiro de insultos. São Paulo: Ateliê Editorial, 2002. 363 p.

BOUSFIELD, Derek. Impolitenesse in the struggle for power. In: BOUSFIELD, Derek; LOCHER, Miriam (eds), Impoliteness in Language. Berlin/NY, Mouton de Gruyter, 2008. 346 p. p. 127-153.

BROWN, Penelope; LEVINSON, Stephen. Politeness some universals in language usage. New York: Cambridge University Press, [1978] 1999. 345 p.

CABRAL, Ana Lúcia Tinoco. Reclamação, crítica e advertência nas interações verbais em ambientes virtuais: subjetividade, polidez e atos de fala. In: Gramática e Texto. Estudos Linguísticos, ㄲo․8, junho 2013, revista do Centro de Linguística da Universidade Nova de Lisboa (CLUNL). Lisboa, Edições Colibri, 2013. 308 p. p.91-105.

Interações verbais em ambientes virtuais: cortesia, descortesia e mal-entendido. In: I.R.SEARA, (ed), Cortesia: olhares e (re) invenções. Lisboa, Chiado Editora, 2014. 596 p. p.497-518.

Produção de Materiais para Cursos a Distância: coesão e coerência. In MARQUESI, Sueli Cristina; ELIAS, Vanda Maria da Silva; CABRAL, Ana Lúcia Tinoco (orgs). Interações Virtuais perspectivas para o ensino de Língua Portuguesa a distância, São Carlos, Claraluz, 2008. 208 p. p.157-170.

Negação, intersubjetividade e polifonia: estudo de caso em processos civis. Revista Letras de Hoje, Vol. 51, n. 1. vol 51 n.1 (2016). 201 p. p 55-64. http://revistaseletronicas.pucrs.br/fo/ojs/index.php/f ale/article/view/21556/143. Acesso em 30/07/2016.

MARQUESI, Sueli Cristina; SEARA, Isabel Roboredo. L'articulation entre le descriptif et les émotions dans l'argumentation en faveur de Dominique Strauss-Kahn. In: RABATEL, Alain; MONTE, Michèle; RODRIGUES, Maria das Graças Soares (eds), Comment les médias parlent des émotions l'Affaire Nafissatou Diallo contre Dominique Strauss-Kahn. Limoges, LambertLucas, 2015. 332 p. p.307-323.
CULPEPER, Jonathan. Reflections on impoliteness, relational work and power. In: BOUSFIELD, Derek; LOCHER, Miriam (eds), Impoliteness in Language. Berlin, NY, Mouton de Gruyter, 2008. 346 p. p.17- 44

DOURY Marianne. A refutação por acusação de emoção: exploração argumentativa da emoção em uma discussão de caráter científico. In MACHADO, Ida Lúcia; MENEZES, William; MENDES, Emília (org.) As emoções no discurso, v.1, Rio de Janeiro: Lucerna, 2007. 335 p. p. 188 200.

EGGINS, Susan. An introduction to systemic functional linguistics. London: Pinter, 1994. 360 p.

HOUAISS, Antônio. e VILAR, Mauro de Salles. Dicionário Houaiss da Língua Portuguesa. Rio de Janeiro: Objetiva, 2001. 2922 p.

KERBRAT-ORECCHIONI, Catherine. Les interactions verbales 1. Paris: Armand Colin, [1990],1998. 315 p.

Les Interactions verbales, tome II. Paris : Armand Colin, 1992. 318 p.

L'énonciation. Paris, Armand Colin, [1980] 1997. $290 \mathrm{p}$.

Le discours en interaction. Paris, Armand Colin, 2005. 365 p.

LOCHER, Miriam ; WATTS, Richard. Relational work and impoliteness : Negotiating norms of linguistic. In: BOUSFIELD, Derek; LOCHER, Miriam (eds), Impoliteness in Language. Berlin, NY, Mouton de Gruyter, 2008. 346 p. p.77-99.

MICHELI, Raphaël. Quand l'affrontement porte sur les mot en tant que mots : polémique et réflexivité langagière. SEMEN Révue de sémio-linguistique des textes et discours. 31. Toulouse : Presses Universitaires de Franche-Comté, 2011, 204 p. p.97-112.

NEVES, Maria Helena de Moura. Gramática de usos do português, 2000. $1037 \mathrm{p}$.

\section{Corpus}

Blog do Sakamoto: < http://blogdosakamoto.blogosfera.uol.com.br/2016/ 07/21/o-governo-nao-faz-a-minima-ideia-do-queseja-terrorismo/ > Acesso em 25/07/2016.

Página do Facebook: < https://www.facebook.com/leonardo.sakamoto/?fre $\mathrm{f}=\mathrm{ts}>$ Acesso em 25/07/2016. 


\section{COMO CITAR ESSE ARTIGO}

CABRAL, Ana Lúcia Tinoco; LIMA, Nelci Vieira de. ARGUMENTAÇÃO E POLÊMICA NAS REDES SOCIAIS: O PAPEL DE VIOLÊNCIA VERBAL. Signo, Santa Cruz do Sul, v. 42, n. 73, jan. 2017. ISSN 1982-2014. Disponível em: <https://online.unisc.br/seer/index.php/signo/article/view/8004>. Acesso em: http://dx.doi.org/10.17058/signo.v42i73.8004. 